\title{
Integrated GPR and Passive Seismic Investigations at Cultural Heritage sites: Case Studies in Malta
}

\author{
R. Persico, L. Matera \\ Affiliation Institute for Archaeological and Monumental \\ Heritage IBAM-CNR \\ Via Monteroni campus Universitario, 73100, Lecce, \\ Italy \\ r.persico@ibam.cnr.ut,1.matera@ibam.cnr.it
}

Abstract- In this paper we report results from an integrated measurement campaign performed on the island of Malta. Both GPR and seismic noise data were gathered in two sites close to the sea, where two watchtowers built by the Order of St. John are located. The two investigations were performed on the top of the cliff inGolden Bay, close to the Ghajn Tuffieha Tower, and at the Madliena Tower in Pembroke. The main goal of the survey was to investigate the possible presence of natural or man-made elements that might affect the preservation of these monuments in the future. The investigations were therefore both on the two historical buildings and on a portion of soil nearby to also check the geological stability of the cliff since the towers are located right on its edge. The measurements were carried out with an innovative stepped frequency GPR system and with passive seismic instrumentation. In the following the main achievements will be presented.

Index Terms-GPR, passive seismic, watchtowers.

\section{INTRODUCTION}

Monitoring for preservation of monuments is an issue of interest in GPR prospecting and, more generally, in integrated geophysical prospecting. In particular, the safeguarding of monuments can be helped by preventive monitoring, possibly identifying problems related to internal cracks, or buried cavities before they become critical [1-3]. At the same time, such monitoring can provide information of cultural interest about the past history of the monument, its modification, the possible presence of walled anomalies, buried crypts, and so on [4-6]. In July 2015, an integrated measurement campaign was conducted in Malta, investigating, among other things, an area close to the Ghajn Tuffieha Tower, on top of the cliff in Golden Bay, and the inner part of the tower of Pembroke, also beside the sea at another point in the island. The Ghajn Tuffieha tower is part of the fortification structures built by the knights of St. John. In particular, it belongs to the "Lascari towers" built between 1637 and 1652 and commissioned by the Italian knight Giovanni Paolo Lascaris, who was Grand Master of the Order at that time. The Madliena Tower is a mighty structure, exploited in the past as a watchtower and built between 1658 and 1659 with very thick walls since it was a military defensive tower.

\author{
S. D’Amico, R. P. Borg, P. Galea \\ Department of Geosciences, University of Malta \\ Msida MSD 2080, Msida, Malta, \\ sebastiano.damico@um.edu.mt,ruben.borg@um.edu.mt, \\ pauline.galea@um.edu.mt
}


Fig. 2. Upper panel: The Ghajn Tuffieha Tower and the prospected area close to it on top of the cliff of Golden Bay. Lower panel, the Madliena Tower close to Pembroke 
In Fig. 1, the location of the two areas is provided, whereas in Fig. 2 an image of the two monuments is shown.

Nowadays, there is some concern about the condition of the cliff in the proximity of the tower of Ghajn Tuffieha, and cliff erosion might damage or destroy the monument in future. In particular, the prospected area, identified by the rectangle shown in Fig. 2 (left hand panel), was selected to investigate superficial traces of a subsidence. In contrast, there was an interest in checking the stability and condition of the Madliena Tower, which underwent a restoration in recent years. To monitor these testimonies of the past, a campaign of GPR and passive seismic prospecting was performed in collaboration between the University of Malta and the Institute for Archaeological and Monumental Heritage IBAM-CNR, and the results are presented below. The paper is organized as follows: in the next section the prospecting is described, the results are shown and interpreted in light of the integrated survey performed, and then conclusions follow.

\section{RESULTS AT THE GHAJN TUFFIENA TOWER}

We acquired our GPR data by making use of a prototypal stepped frequency system [7]. The area is affected by the presence of later spreading and, as previously mentioned, the cliff edge has retreated due to the fracturing of the Upper Coralline Limestone (UCL) overlaying the Blue Clay.

The prospected rectangle is approximately indicated on the Google map in Fig. 2. This area was chosen because of the presence of large fractures in nearby. Fig. 2 also shows the location of the single-station measurements (stars) and the points where $\mathrm{H} / \mathrm{V}$ results were obtained, while Fig. 3 shows the results achieved from the passive seismic measurements. The $\mathrm{H} / \mathrm{V}$ is a common tool used for site effects investigations and is based on the ratio of the horizontal over vertical spectral component of ground motion. Generally, this spectral ratio exhibits a peak that corresponds to the fundamental frequency of the site. In particular, notable characteristics may be identified for each area. The first important observation is the presence of a ubiquitous resonance peak at between 1.0 and $2.0 \mathrm{~Hz}$ and a dip in the spectral ratio below 1.0 over a wide frequency range. This is not surprising because previous ambient noise studies have repeatedly confirmed that all areas of the Maltese islands where UCL outcrops are underlain by a layer of Blue Clay (BC) exhibit a peak in the H/V of this consistent frequency. Reference [8] interprets the dip in the $\mathrm{H} / \mathrm{V}$ ratio in terms of a shallow shear-wave velocity inversion, which in this case corresponds to the interface between the UCL and $\mathrm{BC}$. The interpretation of other features of this peak in terms of Rayleigh wave ellipticity and/or trapping of $S H$ waves in the low-velocity layer is the subject of an ongoing study using numerical modeling. When moving from the inland area towards the cliff edge and rock sliding area, the nature of the $\mathrm{H} / \mathrm{V}$ response changes strikingly. On the plateau away from the cliff edge, the site response shows only the simple and consistent peak at around $1.5 \mathrm{~Hz}$ as described above, while the rest of the $\mathrm{H} / \mathrm{V}$ amplitudes remain at a level well below 2.0 (top left graph panel). Moreover, it is observed that at higher frequencies of the spectrum there are peaks not observed on the plateau area that may be tentatively associated with mechanical vibration modes of the whole blocks.

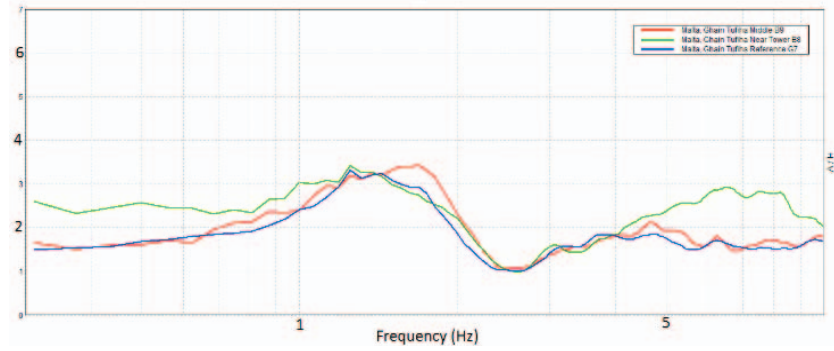

Fig.3. H/V curves obtained at the three different sites. See [10] for details

The area investigated using the GPR can be approximated to a rectangle of size about $5.2 \times 6.5$ meters (Fig. 2), and has been prospected with Bscans parallel to each other, directed toward the sea and spaced $40 \mathrm{~cm}$ apart. The Bscans end in proximity to the cliff, which is about 30 meters high, sharply overhanging the sea. On the top of the cliff, some naturally opened holes witness the possibility of the presence of deep fractures in the cliff, which might one day lead to some collapse. Two of these subsidence points are indicated with arrows in Fig. 2, and as can be seen they are quite well aligned with each other.

In Fig. 4 horizontal slices achieved at different time depth levels are reported, showing that the subsidence has a deep track. In this case, low frequency equivalent antennas have been exploited (with band ranges from about 50 to 350 $\mathrm{MHz}$ ), because the target anomalies are quite extended and it was of interest to increase the penetration depth of the signal. The processing involved zero timing, gain vs. the depth, background removal, and slicing [9]. For the slices, an averaging on $5 \mathrm{~ns}$ of depth range was exploited. No migration was necessary as the anomalies are quite large. The processing was performed using the Reflexw commercial code.

From Fig. 4, it can be appreciated that the two areas evidencing subsidence (especially the lower one) extend to some depth, but at the moment they do not appear to be connected to each other. However, they could be in a future if the phenomenon is progressive.

Let us outline that the conversion time depth was done on the basis of the fact that the cliff is made of limestone. In particular, a propagation velocity equal to $\mathrm{v}=0.1 \mathrm{~m} / \mathrm{ns}$ was exploited for the time-depth conversion.

Indeed, the Bscan did not show any meaningful hyperbola associable to a small target, so that the method of using diffraction hyperbolas would have been unreliable. We also did not have at our disposal the separable antennas needed to perform a CMP measure. 


\section{RESULTS AT THE MADLIENA TOWER}

The inside of the tower at the ground floor level is a rectangle of just $2.9 \times 3.9$ meters, plus a small corridor toward the door. We have prospected this room, with interline step of $20 \mathrm{~cm}$. We exploited also an option of the instrument that allows the handle to be assembled in a perfectly vertical position. In fact, in general the handle of a GPR is slightly oblique, because in this way the human strength needed to push the instrument is dynamically better exploited.

However, while this is useful and in many cases indispensable when prospecting is performed on grass. Indoor, the mechanical resistance to the rotation of the wheels is customarily much lower, and a vertical handle in these cases allows for safe working space and the prospection of a larger proportion of the room.

The data were gathered using the instrument's high frequency antennas (the band ranges being from about 250 and $700 \mathrm{MHz}$ ) and the processing was the same as in the previous case, namely involving zero timing, background removal, gain vs. the depth, and slicing. No migration was performed. In Fig. 5 depth slices at different time depths are shown. The data were not migrated due to a lack of precise information about the propagation velocity. The GPR results suggest the presence of a foundation, with the walls extending (and possibly still enlarging toward the inner part) underground at least to a depth of $1 \mathrm{~m}$, but probably deeper still (here the lack of a precise value for the propagation velocity of the waves prevents more detailed evaluations). In fact, the main reflections are displaced all around the room toward the walls. This suggests a foundation possibly excavated directly in the rock, as a trench. No particular anomalies beyond these ones have been identified.

The tower has also been probed with a passive seismographic device, and the results are summarized in Fig. 6. In particular, measurements were taken at the top level, at the middle level, and also on the ground floor. The $\mathrm{H} / \mathrm{V}$ curve taken on the ground floor confirms that the tower is located on solid rock and as seen in other studies the $\mathrm{H} / \mathrm{V}$ curve gives a flat response [10]. The very highfrequency peaks (between 100 and $200 \mathrm{~Hz}$ ) can be interpreted as a thin layer of soil as shown by the GPR. However, further investigations and numerical modeling are needed in order to confirm such a hypothesis. Figure $6 \mathrm{~b}$ shows the H/V obtained at the roof level. The fundamental frequency, which is the lowest frequency of the building, is clearly identified in this case for both the longitudinal directions at a frequency of about $6 \mathrm{~Hz}$. On the other hand, higher frequency modes were difficult to identify due to the fact that the structure is not very high.

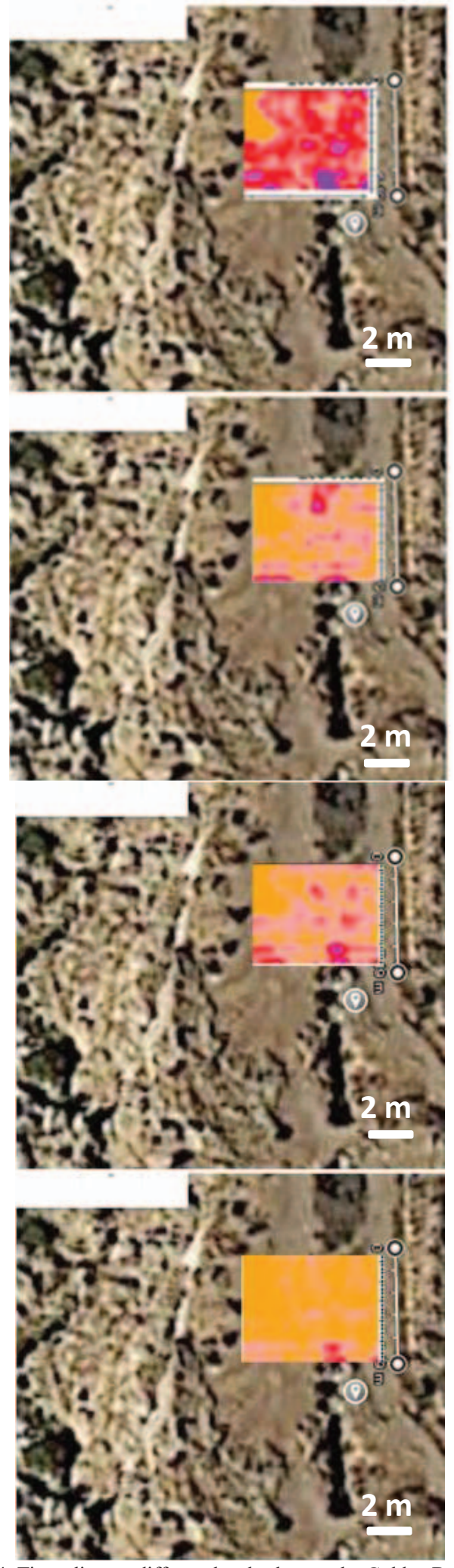

Fig. 4. Time slices at different levels close to the Golden Bay site. From the top to the Bottom: 5, 85, 170 and $280 \mathrm{~cm}$ 


\section{CONCLUSIONS}

In this contribution the results of two measurement campaigns performed with GPR and passive seismic methods have been shown. The campaigns have been performed in or close to the two monuments of the Ghajn Tuffieha Tower and of the Madliena Tower. The results show that the Madliena Tower shows no particular stability problem, whereas the Ghajn Tuffieha Tower is close to a cliff where there are fractures that proved to be quite deep, although they are not at present joined underground. However, the phenomenon could be progressive and some monitoring should be performed in the coming years in order to preserve the tower.

\section{ACKNOWLEDGMENT}

The measurement campaign performed in Malta was possible thanks to the evaluable support of the European Cost Action TU1208. S. D'Amico has been partially supported by the research grant GSCRP02-16 "Multidisciplinary geophysical approaches for the conservation of cultural heritage sites" funded by University of Malta.

\section{REFERENCES}

[1] L. Orlando, E. Slob, "Using multicomponent GPR to monitor cracks in a historical building," Journal of Applied Geophysics vol. 67 issue 4, pp. 327-334, 2009.

[2] S. Piscitelli, E. Rizzo, F. Cristallo, V. Lapenna, L. Crocco, R. Persico and F. Soldovieri, GPR and Microwave Tomography for Detecting Shallow Cavities in the Historical Area of Sassi of Matera (Southern Italy), Near Surface Geophysics, vol. 5, pp. 275-285, 2007.

[3] N. Masini, R. Persico, E. Rizzo, A. Calia, M. T. Giannotta, G. Quarta, A.Pagliuca, "Integrated Techniques for Analysis and Monitoring of Historical Monuments: the case of S.Giovanni al Sepolcro in Brindisi (Southern Italy)," Near Surface Geophysics, vol. 8 (5), pp. 423-432, 2010.

[4 ] E. Utsi, The Shrine of Edward the Confessor: a Study in Multi-Frequency GPR Investigation. In IEEE, 978-1-42444605-6/09, 2009.

[5] M. Pieraccini, L. Noferini, D. Mecatti, C. Atzeni, R. Persico, F. Soldovieri, Advanced Processing Techniques for Stepfrequency Continuous-Wave Penetrating Radar: the Case Study of "Palazzo Vecchio" Walls (Firenze, Italy), Research on Nondestructive Evaluation, vol. 17, pp. 71-83, 2006.

[6] V. Perez-Gracia, O. Caselles, J. Clapes, R. Osorio, I. A. Canas, and L. G. Pujades, "Radar exploration applied to historical buildlings: a case study of the Marqes de Llio Palace, in Barcelona (Spain)," Engineering Failure Analysis, 16(4), 1039-1050, 2009.

[7] R. Persico, G. Prisco, "A Reconfigurative Approach for SFGPR Prospecting," IEEE Trans. On Antennas and Prop., vol. 56, n.8, pp. 2673-2680, August 2008.

[8] F. Panzera, S. D'Amico, A. Lotteri, P. Galea, G. Lombardo, "Seismic site responce of unstable steep slope using noise measurements: the case study of Xemxija bay area, Malta," Natural Hazard and Earth Science System, 12, 3421-3431, doi:10.5194/nhess-12-3421-2012, 2012.

[9] R. Persico, Introduction to Ground Penetrating Radar, Inverse Scattering and Data Processing, Wiley, 2014.

[10] F. Panzera, S. D'Amico, P. Galea, G. Lombardo, M. R. Gallipoli, S. Pace, Geophysical measurements for site response investigation: preliminary results on the island of Malta, Bollettino di Geofisica Teorica ed Applicata, 54(2), 111-128.doi:10.4430/bgta0084, 2013.

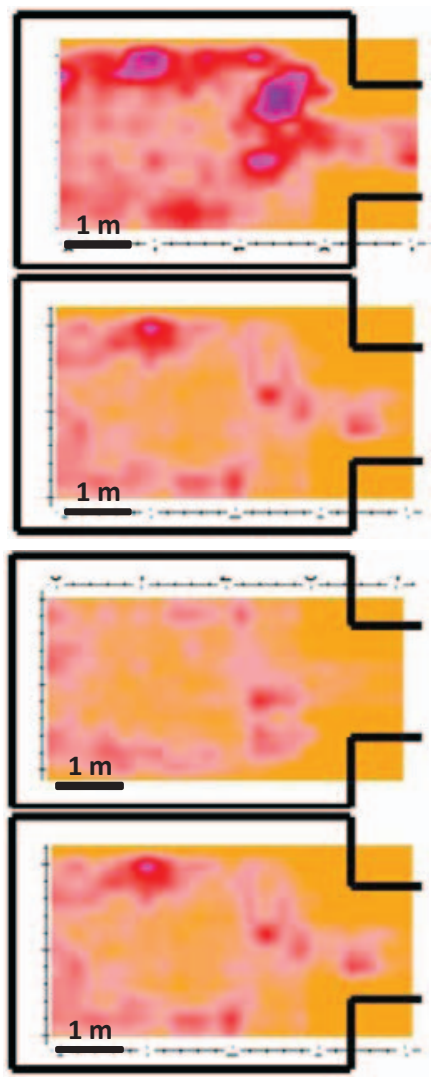

Fig. 5. Time slices at different levels in the room at the ground floor of the Madliena tower. Depth levels from the top to the bottom: 30, 62, 96, $125 \mathrm{~cm}$. The vertical side of the room is $2.9 \mathrm{~m}$ and the horizontal one is $3.9 \mathrm{~m}$.
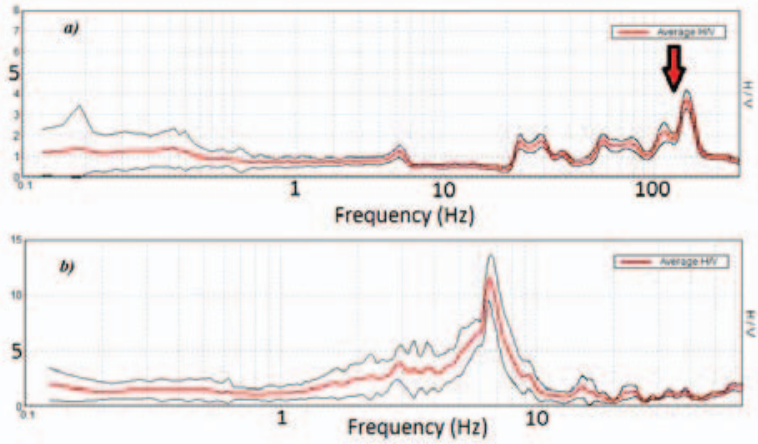

Fig. 6: Seismographic results in the Madliena tower. The top and bottom panels show the results obtained on the ground floor and at the roof level respectively (see text for details) 